\title{
¿Por qué motivos emigran los españoles? Tipología y evolución reciente
}

\author{
Juan Manuel Romero Valiente
}

\author{
Universidad de Huelva, España
}

Resumen

En este trabajo se estudian los motivos por los que emigran los españoles, procediéndose a su tipificación, caracterización, valoración y análisis de su evolución reciente. Para ello toma como base fundamentalmente los datos e informaciones primarias obtenidas a través de una encuesta cuantitativa y entrevistas semi-estructuradas realizadas a algo más de cuatro mil emigrantes españoles. Se concluye que los motivos laborales y económicos han sido los principales impulsores del crecimiento de la emigración en los últimos años. Durante el segundo lustro de la primera década del siglo actual han sido los relacionados con la mejoría económica y el desarrollo profesional los principales protagonistas de este proceso. Desde principios de la década actual, el desempleo y la falta de oportunidades en España se han convertido en los motores y catalizadores del mismo.

Palabras clave: Emigración española, motivos, desempleo, desarrollo profesional.

Abstract

On what grounds migrate Spanish? Typology and recent developments

In this paper the reasons for migrating Spaniards Provisions are typing, characterization, assessment and analysis of recent developments are discussed. To do essentially builds on primary data and information obtained through a quantitative survey and semi -structured interviews with more than four thousand Spanish emigrants. We conclude that labor and economic reasons were the main growth drivers of migration in recent years. During the second half of the first decade of this century it has been those related to economic improvement and professional development the key players in this process. Since the beginning of the current decade, unemployment and lack of opportunities in Spain have become engines and catalysts of the same.

Key words: Spanish emigration, reasons; unemployment, professional development. 


\section{INTRODUCCIÓN}

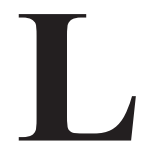

a emigración de españoles al exterior ha constituido desde el último tercio del siglo XIX hasta mediados de la década de los 70 del siglo XX uno de los fenómenos que más ha incidido en el desarrollo social y económico de España. Durante el último cuarto del siglo XX y los primeros años del presente siglo este fenómeno se ha reducido sensiblemente en magnitud y opacado además por el enorme impulso que ha experimentado la inmigración, tanto en forma de retorno de españoles como, sobre todo, de llegada de extranjeros. En este período podría casi decirse que España pasó de ser un país de emigración a otro de inmigración.

Desde mediados de la primera década del siglo actual la emigración española comienza a experimentar un cambio de tendencia que se traduce en un crecimiento prácticamente continuado del número de salidas hasta la actualidad. Es, no obstante, desde finales de dicha década e inicios de la presente, coincidiendo con el inicio de la crisis económica y progresiva agudización de sus efectos, cuando el ritmo de crecimiento se acelera, elevándose sustancialmente el número de salidas que alcanza en 2011 cifras que no se registraban, al menos en las estadísticas oficiales, desde 1975 (Romero Valiente, 2012).

En los últimos años el flujo emigratorio ha seguido creciendo, situándose, según las estadísticas que publica el Instituto Nacional de Estadística de España (INE) —Estadística de Migraciones (EM), Estadística de Variaciones Residenciales (EVR) - algo por encima de los ochenta mil en 2014, el doble que en 2010, y cerca de los cien mil en 2015 (Figura 1). Las magnitudes de este fenómeno son, sin duda, superiores a las que indican las estadísticas oficiales, posiblemente en torno al doble, debido al notable sub-registro consular — en el Padrón de Españoles Residentes en el Extranjero (PERE) — que afecta especialmente a los emigrados más jóvenes y quienes tienen como destino países de la Unión Europea (Romero Valiente, 2012; Romero Valiente e Hidalgo-Capitán, 2014; Romero Valiente, 2016; Romero Valiente, 2017; Romero-Valiente, 2018).

Este notable, y en buena parte inesperado, crecimiento de la emigración española en los últimos años, ha suscitado una importante preocupación social y atención mediática, entrando con cierta fuerza incluso en la arena política. 
Figura 1: Emigración de españoles al exterior 2002-2015. Datos absolutos

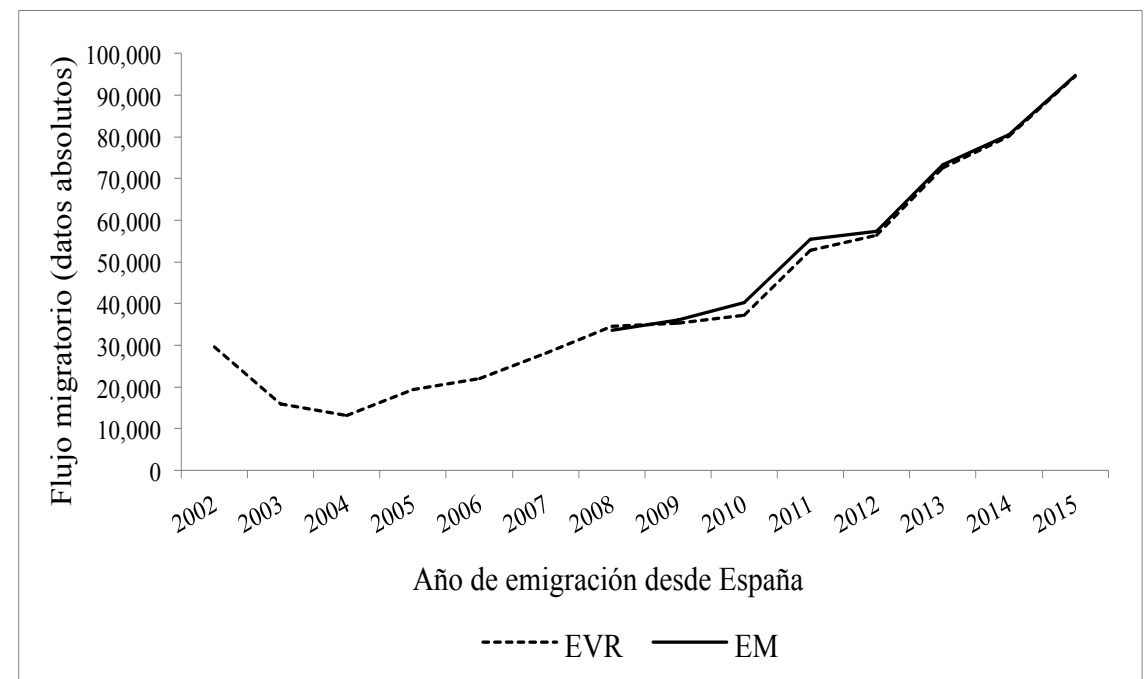

Fuente: elaboración propia con base en EVR y EM, INE.

En este sentido, cabe reseñar que se mantiene desde el principio de la detección de este fenómeno un importante debate y controversia tanto sobre las magnitudes y dimensión demográfica del mismo, como de las causas y motivaciones que lo alientan.

¿Por qué emigran actualmente los españoles? ¿Cuáles son motivos que alientan principalmente este proceso y qué peso específico tienen en el mismo? ¿Este peso se ha mantenido relativamente estable en las últimas décadas y a lo largo del siglo actual, o se han producido cambios importantes? ¿Qué ha pasado en este sentido desde el inicio de la crisis?

Este trabajo trata de dar respuesta a las preguntas anteriores, aportando su granito de arena a la mejora del conocimiento de las causas de la emigración española en general y de la que se está produciendo en los últimos años en particular. Este trabajo se justifica por varias razones. Por un lado, la escasez de investigaciones que abordan este tema a partir de una amplia base de datos e informaciones procedentes directamente de los protagonistas de la emigración, y no especulaciones sustentadas básicamente en fuentes secundarias e indirectas. Por otra, la inexistencia de investigaciones que aborden este fenómeno con cierta perspectiva temporal, que no se ciñan exclusivamente a la emigración de los últimos años, sino que, aún prestándole en razón de sus dimensiones, mayor atención a la misma, la sitúe y contextualice adecuadamente en un marco evolutivo más amplio. Máxime 
teniendo en cuenta que la emigración comienza a crecer a mediados de la primera década del siglo actual en un contexto de elevado crecimiento económico y reducción del desempleo.

La población de referencia de este trabajo la constituyen los españoles, nacidos en España, que han emigrado del país con edades comprendidas entre los 18 y 64 años. Se ha prestado especial atención a los emigrados en las últimas décadas, particularmente los que lo han hecho en el siglo actual y, sobre todo, desde el inicio de la crisis económica. El concepto de emigrante utilizado, tanto en la encuesta como en este trabajo, es el de migrante por largo plazo tal como ha sido definido por las Naciones Unidas (United Nations, 1998: 10) y el Reglamento 862/2007 de la Unión Europea (2007: 24). ${ }^{1}$

\section{MARCo TeÓRICO Y ESTAdo de La CUESTIÓN}

Las migraciones se suelen explicar atendiendo a factores generales, frecuentemente de carácter socioeconómico, que estarían detrás de los motivos directamente implicados en la decisión de migrar. Los primeros contribuirían a explicar las tendencias más generales de la dinámica migratoria, mientras que los segundos pondrían en valor las dimensiones individuales y microsociales del proceso, posibilitando observar mejor los matices del mismo y el establecimiento de tipologías y perfiles de sus protagonistas. Ambos enfoques son útiles y complementarios para la comprensión correcta del fenómeno. ${ }^{2}$ Mientras que el primero prepara "el escenario", el segundo "representa la acción" (Ebanks, 1993: 40). Estos últimos representan lo se ha venido en denominar "enfoque motivacional" de los estudios migratorios (De Jong and Gardner, 1981; Fawcett and De Jong, 1982), el cual se utiliza fundamentalmente en este artículo.

En lo que respecta a la emigración española contemporánea (especialmente entre 1875 y 1975), gran parte de los trabajos llevados a cabo para

\footnotetext{
${ }^{1}$ Las Naciones Unidas definen como migrante por largo plazo a "toda persona que se traslada de un país distinto de aquél en el que tiene su residencia habitual por un periodo de por lo menos un año". El Reglamento CE no 862/2007 define como emigrante a aquella "persona, que habiendo sido previamente residente habitual en el territorio de un Estado miembro, deja de tener su residencia habitual en ese Estado miembro por un periodo que es, o se espera que sea, de al menos doce meses".

2 "No se pueden sobrevalorar los motivos individuales en detrimento de las causas estructurales cuando se trata de comprender el fenómeno de la migración, así como tampoco se puede prescindir del primero considerando sólo el segundo orden de factores" (Jannuzzi, 2000: 50). "Migration analysis should be concerned not only with the reasons why people move or do not move, but also with the reasons why some places do or do not send or receive migrants. Thus, in migration studies it is equally important to associate the information derived from households and individuals with information on the communities in which they reside in order to know how the community-level and individual-level factors interact to affect the migration decision" (United Nations, 1982:10).
} 
explicar sus causas lo han hecho prestando especial atención a los factores generales (Vázquez y Estrada, 1992; Palazón, 1995; Sánchez Alonso, 1995). Son menos, sin embargo, lo que prestan una especial atención a las motivos específicos de la decisión de emigrar directamente expresados por sus protagonistas (Rubio, 1973; Fernández de Pinedo, 1988; Vidal Rodríguez, 2005; entre otros). Ello tiene, mucho que ver, sin duda, con la posibilidad de disponer de datos sobre los motivos para emigrar obtenidos a través de encuestas y/o informaciones sobre el particular recogidas en testimonios de los protagonistas.

Algo similar ocurre en lo que respecta a la emigración española de las últimas décadas del siglo XX y los primeros años del siglo actual (prácticamente olvidada ${ }^{3}$ y, por ende, la más reciente, la cual ha generado un renovado interés por el tema y está dando lugar a diversas aportaciones. En varios trabajos sobre la emigración actual se hace referencia a los motivos que inducen a los españoles a emigrar (OIM, 2012; González Ferrer, 2013; González Enríquez, 2013), e incluso en algunos, basados en encuestas, se procede a una valoración del peso relativo de los mismos (INJUVE, 2013; Faraco et al., 2013; OIM, 2014; González y Martínez, 2014). En casi ningún caso, sin embargo, se lleva a cabo una tipificación y caracterización detallada de los mismos, un análisis de su evolución en estos últimos años, así como su contextualización en el marco de la emigración española de las últimas décadas.

En los últimos años también se han publicado datos y análisis específicos sobre los motivos para emigrar en el caso de ciudadanos de otros países que residen fuera de los mismos (Murray et al., 2012; MacAleer, 2013; Glynn et al., 2013; Triandafyllidou and Gropas, 2014; Biacabe et Robert, 2014). Buena parte de ellos se han llevado a cabo respondiendo, sobre todo, a una preocupación generalizada por la denominada "fuga de cerebros" y a la alarma social suscitada por la misma. Solo en el caso del estudio realizado por la Universidad de Cork (Glynn et al., 2013), basado en una encuesta a 1.513 irlandeses residentes en el extranjero, se ofrecen datos sobre la evolución entre 2008 y 2013 del peso de los distintos motivos en la emigración.

Sea como fuere, en los estudios realizados en España y estos países se pone en evidencia tanto el elevado nivel de formación de los nuevos emigrantes, como la destacada importancia que están teniendo los motivos

\footnotetext{
${ }^{3}$ Los pocos trabajos llevados a cabo en estos años se han centrado más en el stock de población española residente en el extranjero (MTySS, 1986; Reques y de Cos, 2003; Romero Valiente, 2003) y los procesos de retorno (Castillo, 1981) que en el flujo emigratorio, salvo en casos puntuales de determinados países (Romero Valiente, 1998 y 1999).
} 
laborales, con los matices correspondientes en cada caso, en la decisión de emigrar.

\section{Fuentes Y METODOLOGÍA}

Para la aproximación al fenómeno en estudio y tratar de alcanzar los objetivos anteriormente indicados se ha utilizado una metodología mixta y de carácter triangular (Cantor, 2002) que combina la utilización de diversas fuentes (primarias y secundarias) y herramientas de análisis.

\section{Fuentes primarias}

Para el estudio de los motivos por los que emigran los españoles se ha contado con una amplia base informativa obtenida a partir de los testimonios y respuestas de los propios protagonistas, así como de informantes-clave y observadores privilegiados del fenómeno (directivos de asociaciones españolas en el extranjero, miembros de representaciones diplomáticas, etc.). Estos datos e informaciones han sido obtenidos fundamentalmente a través de entrevistas semi-estructuradas (con preguntas abiertas) y una encuesta de carácter cuantitativo (con preguntas, en su gran mayoría, cerradas).

\section{La información de carácter cualitativo de las entrevistas semi-estructuradas}

Con el objeto de conocer mejor y más directamente el fenómeno en estudio, y que la información recogida sirviera de base para la adecuada preparación de una encuesta de carácter cuantitativo, se llevó a cabo un estudio exploratorio basada principalmente en la realización de entrevistas semi-estructuradas a emigrantes españoles. El instrumento básico para la recogida de información fue un cuestionario de trece preguntas abiertas, que fue ampliamente difundido entre la población en estudio utilizando todos los medios disponibles (redes sociales, listados de correo electrónico, instituciones españolas en el exterior, etc.).

Como resultado de este proceso, que se extendió en el tiempo (junio 2011 - septiembre 2012) en virtud del éxito que se iba obteniendo (inesperado en sus magnitudes) y la continua ampliación de contactos, se realizaron 2031 entrevistas (autoadministradas en su mayor parte) a españoles residentes en el extranjero, en su gran mayoría emigrados desde España, así como también a algunos que habían retornado a nuestro país. En los casos en los que se consideró de interés (por el perfil del entrevistado, la naturaleza de la información, etc.) y fue factible (por la buena disposición 
del entrevistado), una vez cumplimentado el cuestionario básico se contacto de nuevo con los entrevistados (a través de e-mail, Skype, Facebook) para que respondieran a otras preguntas sobre el tema en estudio.

En el cuestionario básico se incluyó una pregunta específicamente destinada a conocer las causas de la emigración. Las respuestas ofrecidas por los entrevistados, en algunos casos muy amplias, constituyen una información muy rica y valiosa sobre el tema en estudio. En este artículo han sido utilizadas principalmente para contrastar y comprender mejor los datos sobre los motivos de la emigración que ofrece la encuesta cuantitativa, así como documentar, a través de los propios testimonios de los emigrados, los adoptados para dicha decisión. En estos testimonios se puede constatar, además, la coexistencia, en muchos casos, de diversos motivos en la decisión de emigrar de España.

\section{Los datos de la encuesta de carácter cuantitativo}

Tomando como base la información obtenida en el estudio exploratorio se diseñó una encuesta con el fin de recoger datos de carácter cuantitativo a través de internet. ${ }^{4}$ Los procedimientos seguidos para su elaboración e implementación han sido explicados con detalle en otros trabajos (Romero Valiente 2012; Romero-Valiente e Hidalgo-Capitán 2014; Romero Valiente, 2017) y se resumen en la ficha técnica que aparece a continuación.

- Universo: españoles mayores de edad que llevan residiendo al menos un año (o tienen intención de hacerlo) en el extranjero.

- Tamaño de la muestra: 4058 entrevistas válidas —residentes en 120 países ( 2417 correspondientes a nacidos en España emigrados entre 2001 y 2012 con edades entre 18 y 64 años).

- Método de muestreo: no probabilístico por autoselección.

- Recogida de información: encuesta on-line asistida por un sistema CAWI (Computer Assisted Web Interviewing).

\footnotetext{
${ }^{4}$ Las ventajas y limitaciones de una encuesta levantada a través de internet ha sido objeto de análisis en diversos trabajos (Cea, 2004; ADM, 2000 y ADM, 2001; Díaz de Rada, 2004; Díaz de Rada, 2010; Díaz de Rada, 2011 y Díaz de Rada, 2012; Sánchez Carrión et al., 2012). Entre las ventajas cabe reseñar, sobre todo cuando es diseñada y administrada adecuadamente, la posibilidad de acceder a una población muy dispersa geográficamente y en buena parte oculta, ampliar el tamaño de la muestra, y el incremento sustancial de las tasas de participación y respuesta. Todo ello permite elevar sus niveles de aleatoriedad y representatividad, contribuyendo a reducir sus limitaciones desde el punto de vista estadístico (sesgos, imposibilidad de generalización estadística de sus resultados, etc.). Los datos obtenidos a través de la misma ofrecen, en todo caso, una acumulación de indicios suficientes (saturación) sobre el objeto de investigación que confieren una notable validez a sus resultados. Esta metodología es, en cualquier caso, actualmente la más comúnmente utilizada en los estudios que tienen como objetivo conocer las características, situación y problemática de la población emigrante y residente en el exterior (INJUVE, 2013; OIM, 2014; González y Martínez, 2014).
} 
- Fechas de realización (trabajo de campo): junio - septiembre 2012.

En el cuestionario de la encuesta se incluyeron varias preguntas (cerradas y de respuesta obligatoria) destinadas específicamente a conocer las causas de la emigración. En este trabajo se ha utilizado una de ellas, la $\mathrm{Bp} 1$, en la que se recoge información sobre los motivos principales de la emigración (Tabla 1). Los datos obtenidos, relativos a la causa principal de emigración al país de residencia actual (primera columna, CAMIGR1), constituyen la base fundamental de los análisis que se realizan en este trabajo.

Tabla 1: Bp1. ¿Cuáles fueron las principales causas de su migración/desplazamiento al país de residencia actual? (Puede elegir un máximo de dos respuestas; ordénelas en función de la importancia para su migración/desplazamiento) (Por favor, marque sólo una opción en cada columna)

\begin{tabular}{|c|c|c|}
\hline \multirow[b]{2}{*}{ Cód. } & \multirow[b]{2}{*}{ Causas de la migración/desplazamiento } & $\begin{array}{c}\text { Orden de } \\
\text { importancia }\end{array}$ \\
\hline & & $1^{\circ} \quad 2^{\circ}$ \\
\hline 1 & Aprendizaje / perfeccionamiento de idiomas & \\
\hline 2 & Estudios y formación & \\
\hline 3 & Investigación (contratos/becas postdoctorales, etc.) & \\
\hline 4 & $\begin{array}{l}\text { Destino laboral por institución pública } \\
\text { (nacional/internacional, etc.) }\end{array}$ & \\
\hline 5 & Destino laboral por empresa & \\
\hline 6 & Estar sin empleo / falta de oportunidades laborales & \\
\hline 7 & Mejorar situación/perspectivas laborales y/o económicas & \\
\hline 8 & Motivos familiares y/o de pareja & \\
\hline 9 & Cooperación y ayuda humanitaria & \\
\hline 10 & Retorno a su país de origen & \\
\hline 11 & Otros motivos personales & \\
\hline 12 & Otro/s motivo/s diferente/s a los anteriores & \\
\hline
\end{tabular}

Fuente: elaboración propia con base en la Encuesta sobre la situación de los españoles en el extranjero 2012.

Cabe reseñar, en este sentido, que a la hora de planificar la formulación de esta pregunta y sus posibles respuestas, se optó porque los encuestados debieran indicar la razón o motivo principal por la que llevaron a cabo la migración. ${ }^{5} \mathrm{Y}$ ello, por dos razones. Por una parte, porque la multi-respuesta (aunque fuese hasta un máximo de tres como se hace en muchos casos) no permite discriminar la jerarquía entre motivos, otorgando no pocas veces un peso excesivo a aspectos que no son centrales (AEC, 2014: 106) pero que pueden estar presentes (denominadores comunes) en una

${ }^{5}$ Esta opción ha sido la adoptada en muchas encuestas sobre migración realizadas en distintos países (González Becerril et al., 2012). 
gran parte de los encuestados. Por otra, la identificación del motivo para emigrar más importante (independientemente de que sea el único o su peso específico sea mayor o menor respecto a los que le siguen en la jerarquía), permite establecer mejor una tipología, así como la valoración del peso de los mismos. De otra parte, la reducida proporción de personas que seleccionó como principal motivo para emigrar la respuesta "escoba" (Otros motivos diferentes a los anteriores), viene a corroborar la adecuada selección de las posibles respuestas en orden a cubrir la diversidad y amplitud del fenómeno investigado.

Los datos obtenidos han sido objeto de una exhaustiva explotación utilizando los programas Excel y SPSS. Los datos correspondientes a las respuestas a dicha pregunta han sido cruzados con los de otras variables de interés para los objetivos de este artículo, especialmente el año de emigración desde España, también recogidos en la encuesta.

\section{Fuentes secundarias}

Para la adecuada preparación de este trabajo se ha llevado a cabo una revisión exhaustiva de la bibliografía y cualquier otro tipo de documentación disponible sobre las causas y motivos de las migraciones, en general, así como, sobre todo, de la emigración española y, complementariamente, de nacionales de otros países.

Por otra parte, se han utilizado las estadísticas sobre emigración española que publica el INE (EVR y EM). Aún teniendo en cuenta sus limitaciones, anteriormente indicadas, constituyen las únicas de carácter oficial disponibles que ofrecen datos y cifras sobre el flujo de emigración española. En este trabajo han sido utilizadas para cifrar y documentar la evolución temporal del fenómeno en el siglo actual, así como para llevar a cabo la ponderación de los datos obtenidos en la encuesta anteriormente descrita (postestratificación) y tratar con ello de reducir los posibles sesgos derivados del método de recogida de los mismos.

\section{LOS MOTIVOS PARA EMIGRAR}

Aunque la clasificación de los motivos para emigrar no está exenta de dificultades, tomando como referencia las llevadas a cabo en algunos trabajos (Contreras, 2008; entre otros), así como, sobre todo, las respuestas emitidas por los propios emigrados españoles en las entrevistas realizadas (en virtud de su recurrencia, similitudes, etc.), los hemos dividido en dos grandes tipos: los de carácter laboral y/o económico; y los formativos, familiares y de pareja, personales y de otro tipo (Tabla 2). 
Tabla 2: Tipología de motivos para emigrar

\begin{tabular}{cl}
\hline & \multicolumn{1}{c}{ Motivos para emigrar } \\
\hline \multirow{2}{*}{$\begin{array}{l}\text { Laborales y } \\
\text { económicos }\end{array}$} & Mejorar situación laboral y/o económica \\
& Destino laboral \\
& Cooperación e investigación \\
\hline \multirow{2}{*}{$\begin{array}{c}\text { Formativos, } \\
\text { familiares y otros }\end{array}$} & Formación \\
& Familiares y/o de pareja \\
& Personales y otros \\
\hline
\end{tabular}

Fuente: elaboración propia con base en la Encuesta sobre la situación de los españoles en el extranjero 2012.

Los datos e informaciones obtenidas a través de las fuentes anteriores ponen de relieve la existencia de motivos diversos ${ }^{6}$ entre los emigrados españoles para trasladar su residencia desde España a otro país. Su peso específico en la decisión de emigrar ofrece, no obstante, variaciones significativas en función del año/periodo de salida de España (Figura 2), así como de las características socio-demográficas y perfil de los emigrados. Este artículo se ocupa principalmente de las primeras.

\section{Laborales y/o económicos}

Los motivos laborales y/o económicos han constituido y constituyen el principal motor de las migraciones internacionales (OIM, 2013: 49). Según la Organización Internacional del Trabajo (OIT), la migración laboral ha crecido, además, a nivel mundial en los últimos años (ILO, 2015). En el caso de la emigración española, los datos procedentes de diversas fuentes y la literatura existente ponen en evidencia la importancia fundamental de estos motivos en las principales corrientes y oleadas de nuestra historia, así como el crecimiento de su protagonismo en los últimos años.

Los datos de nuestra encuesta vienen a corroborar este último hecho. Entre los españoles encuestados que emigraron en el último cuarto del siglo XX y el primer lustro del siglo actual, este tipo de motivos es esgrimido por algo más de 40 por ciento como principal causa de salida de España. Esta proporción se eleva a 50 por ciento entre quienes emigran en 20062008 , a 55 por ciento entre 2009-2010, a 60 por ciento en 2011, y casi 70 por ciento en 2012.

\footnotetext{
6 “... la decisión de emigrar es un constructo multidimensional que depende de varios motivos donde la economía, la formación y el desarrollo personal son especialmente importantes" (Gómez-Frías et al., 2015).
} 
Figura 2: Tipo principal de motivos para emigrar de España 1976-2012, según año (período) de salida

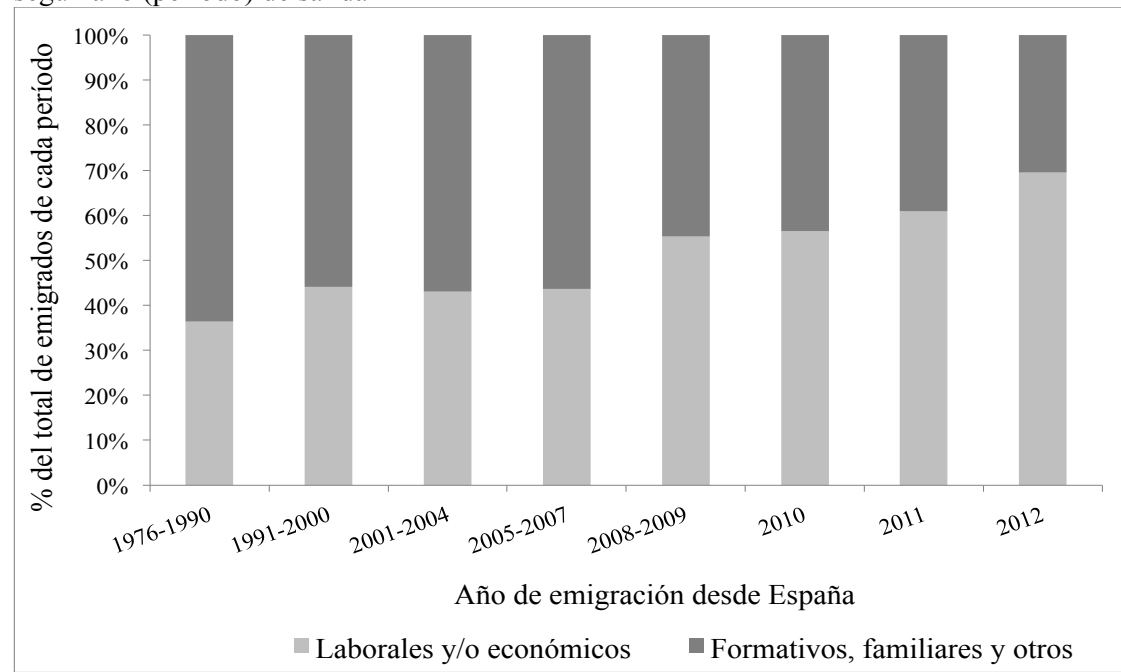

Fuente: elaboración propia con base en la Encuesta sobre la situación de los españoles en el extranjero 2012.

El análisis de los datos de manera más desagregada permite apreciar, no obstante, diferencias significativas en el papel ejercido en el flujo emigratorio por los diversos motivos que integran este amplio subconjunto (Figura 3). En los años centrales y durante el segundo lustro de la primera década del presente siglo, los motivos relacionados con el desplazamiento y la expatriación (en sus modalidades diversas), así como la mejoría laboral y/o económica, son los principales responsables del crecimiento. Desde los años finales de dicha década, pero sobre todo, inicios de la actual (2011), la falta de empleo y/o de oportunidades laborales se convierte en el principal motivo de emigración y responsable claro de su notable crecimiento.

\section{Estar sin empleo y/o búsqueda de oportunidades laborales}

Este motivo es, sin duda, el que más se relaciona con factores de expulsión tradicionales de carácter laboral y económico, especialmente con la elevación del desempleo y la precariedad laboral. La dificultad o práctica imposibilidad de acceder a un trabajo decente, relativamente acorde a la formación obtenida, así como situaciones de pérdida del mismo debido a cierres de empresas y/o regulación de empleo, constituyen argumentos clave para los emigrados que aducen este motivo como principal causa de salida de España. 
Figura 3: Principal motivo para emigrar de España (laborales y/o económicos) 1976-2012, según año (periodo) de salida

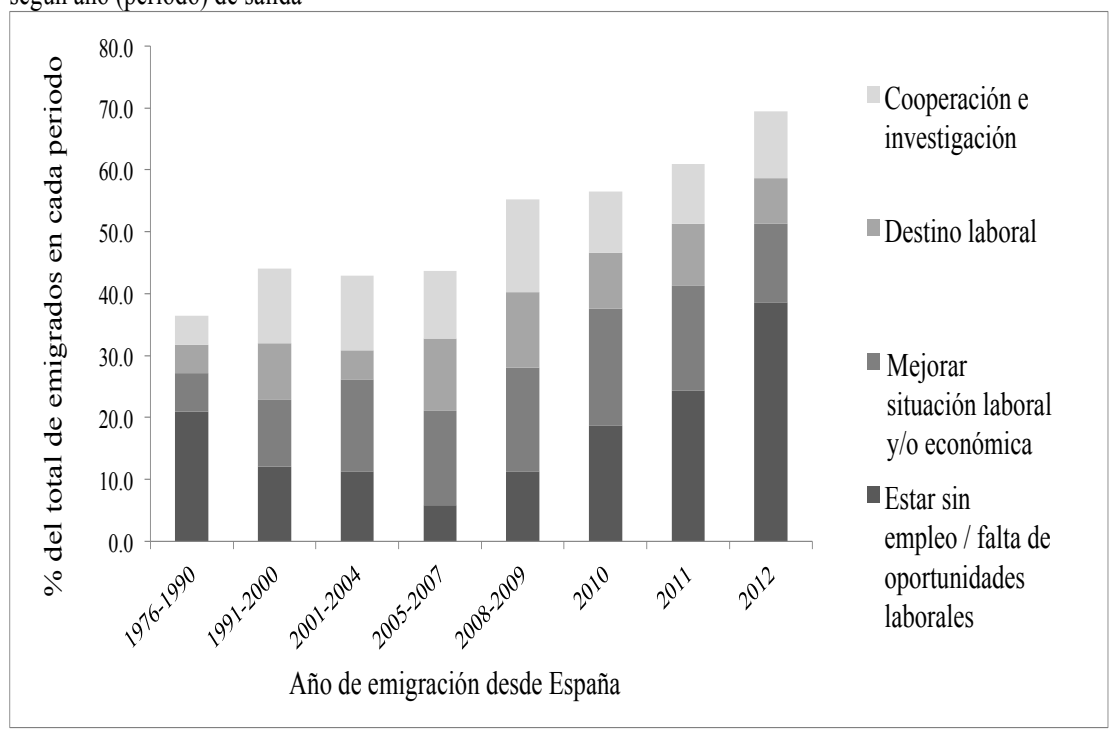

Fuente: elaboración propia con base en la Encuesta sobre la situación de los españoles en el extranjero 2012.

La evolución seguida por la proporción de personas que indican este motivo como principal causa de su emigración es elocuente en este sentido Este motivo reduce progresiva y significativamente su peso en los emigrados en la última década del siglo pasado y, sobre todo, entre 2001 y 2007 coincidiendo con los momentos de mayor bonanza económica y de reducción del desempleo de la historia de nuestro país. Pasa de representar en torno a 20 por ciento entre los que emigran de España entre 1976 y 1990, a algo menos de 15 por ciento entre los que lo hacen en 1991-2000 y 2001-2003, a siete por ciento en 2004-2006 y algo menos de cinco por ciento en 2007. Entre los que emigran a partir de 2008, coincidiendo con el estallido de la crisis económica y la progresiva agudización de sus efectos, dicha proporción inicia una senda ascendente que lo lleva a situarse algo por encima de diez por ciento entre los emigrados en 2008-2009, cerca de 20 por ciento en 2010, de 25 por ciento en 2011 y de 40 por ciento en 2012.

Entre los emigrados en los dos últimos años (2011 y 2012), este motivo se convierte en la principal causa de salida de España, con clara diferencia respecto al resto. El hecho de que sea precisamente en los últimos años del periodo observado cuando la emigración más ha aumentado en términos absolutos, puede dar una idea de la importancia de este motivo en el crecimiento de la misma. Sirva finalmente como dato de referencia que, entre 
los emigrados en 2008-2012, cerca de 25 por ciento indica este motivo como principal causa de salida de España, tres veces más de los que lo hicieron en el quinquenio precedente (2003-2007).

No encontrar trabajo, frustración personal y paso atrás al volver a vivir en el domicilio familiar. Únicas entrevistas de trabajo que hice eran de comercial a puerta fría. Muy mal pagado o ni siquiera pagado, a expensas de la venta (Hombre, emigrado en 2011 al Reino Unido con 25 años).

\section{Mejorar la situación laboral y/ económica}

Mejorar la situación laboral y/o económica es un motivo que puede considerarse, en relación al anterior, como de un nivel inferior en una escala de causas de emigración regida por el grado de preponderancia de las razones económico-laborales en la decisión de cambiar de residencia a otro país. En este caso, la decisión de emigrar no obedece tanto a la inexistencia o escasez de posibilidades económico-laborales en el país de origen, sino a la valoración, a manera de juego de fuerzas, entre éstas y las que ofrecen los potenciales lugares de destino, sobre todo en cuanto a condiciones de empleo y perspectivas profesionales, que se decantan a favor de estas últimas.

La inestabilidad y precariedad laboral en el país de origen, así como el deseo de prosperar, mejorando las condiciones de vida y/o de desarrollo profesional, aprovechando las oportunidades que, en dicho sentido, ofrecen los países de destino, constituyen argumentos básicos de quienes esgrimen este motivo como principal causa de salida de España.

Este motivo mantiene un nivel de prevalencia destacado y relativamente constante como principal causa de salida de España a lo largo del siglo actual, casi siempre, según los datos de la encuesta, en el entorno de 15 por ciento del total. Este motivo incrementa su peso desde mediados de la primera década del presente siglo alcanzando su nivel máximo en 2009-2010 (primeros años de la crisis), en los que se convierte en la principal causa de salida de España. A partir de este año, este motivo pierde peso relativo cediendo protagonismo al anterior. Entre los emigrados a partir de 2011 el motivo principal ya no es mejorar la situación laboral y/o económica, sino buscar salidas y oportunidades en este sentido.

Por trabajo, mejores condiciones de trabajo en Francia, para poder pagar la especialidad en España. Porque hay mucho trabajo de Fisioterapeuta y las condiciones son mejores que en España (Mujer, emigrada en 2009 a Francia con 25 años). 


\section{Destino laboral en el extranjero}

La salida de España debido a un destino laboral en el exterior (sea de una empresa o institución, pública o privada, nacional, extranjera o internacional) constituye una modalidad migratoria que, aunque no es nueva, hundiendo sus raíces en el pasado colonial (Hampe, 1992; Sepúlveda, 1992; Gozálvez Pérez, 1994), ha cobrado mayor vigor en las últimas décadas. Este tema, especialmente el relacionado específicamente con el desplazamiento de capital humano por parte de las empresas en general, y españolas en particular, ha sido y es objeto de numerosos trabajos (Bastida Domínguez, 2007; Pascual y Escalera, 2009).

La proporción de emigrados españoles que indica este tipo de motivos como principal causa de emigración experimenta un importante crecimiento en las últimas décadas. Según los datos de la encuesta, pasan de representar menos de cinco por ciento entre 1976 y 1990, a cerca de diez por ciento en la última década del siglo XX, y de 15 por ciento entre 2006 y 2008. Los datos indican con cierta consistencia, no obstante, que es entre los emigrados en 2008 cuando alcanza sus mayores cotas, cerca de 20 por ciento, reduciendo su peso relativo a partir de entonces a favor de los motivos anteriormente analizados.

Causas de la emigración: ascenso laboral dentro de la misma empresa ¿Por qué elegiste ese país como destino? Sede central de la mencionada empresa (Mujer, emigra en 2008 a Alemania con 33 años).

\section{Cooperación e investigación}

De forma relativamente parecida al anterior, la salida de España por motivos de cooperación e investigación ha incrementado su importancia en las últimas décadas. La emigración por ambos motivos lleva, en no pocos casos, aparejadas intencionalidades formativas y/o de carácter personal. En este sentido podría decirse que se sitúan en un espacio de transición entre la emigración laboral y la que se lleva a cabo por otros motivos. No obstante, el hecho de que ambas modalidades migratorias tengan mayoritariamente como finalidad el ejercicio de una actividad laboral, nos ha llevado a incluirlas dentro de esta tipología de motivos. Por otra parte, cabe significar que tanto una como otra, pero sobre todo la cooperación tiene un reconocimiento en este sentido, incluso desde el punto de vista jurídico, desde hacer varias décadas (Serrano Carvajal, 1966: 132) que ha sido reafirmado con la promulgación del Estatuto del Cooperante en 2007, aún con sus lagunas y deficiencias (Pérez, 2013). 
La proporción de encuestados que indican alguno de estos motivos como principal causa para su salida de España crece progresivamente entre finales del siglo pasado y la primera década del siglo actual. Estos motivos pasan de representar en torno a cinco por ciento entre los emigrados en 1976-1990, a algo más de diez por ciento entre los que lo hacen en la última década del siglo XX, y a cerca de 15 por ciento entre quienes lo hacen entre 2006 y 2009. Entre los emigrados a partir de 2010 su peso relativo se reduce significativamente pasando a representar en torno a diez por ciento del total. Esta evolución guarda probablemente una estrecha relación con el incremento del esfuerzo de las administraciones públicas y otras instituciones españolas (y también extranjeras y de carácter internacional) en materia de becas/contratos de investigación en el extranjero, cooperación al desarrollo y ayuda humanitaria.

Quería hacer una estancia postdoctoral fuera de España, y quería hacerlo independientemente de la situación económica actual, pero se ha convertido en una de las únicas salidas, y ahora es impensable volver (Mujer, emigra en 2010 a Estados Unidos con 34 años).

Causas de la emigración: Por trabajo con una ONGD española. ¿Por qué elegiste ese país como destino? Fue donde surgió la oportunidad de trabajo y tenía interés en vivir en Latinoamérica (Mujer, emigra en 2008 a Nicaragua con 31 años).

\section{Formativos, familiares y otros}

Motivos diferentes a los anteriores también han estado siempre presentes, en mayor o menor medida, a lo largo de la historia de la emigración española, incluso en sus oleadas masivas de $1880-1930^{7}$ y $1960-1975$. No obstante, salvo en períodos muy concretos relacionados con el desarrollo de procesos de reagrupación familiar, es probable que nunca hayan tenido el protagonismo y, sobe todo, la diversidad de las últimas décadas. La literatura existente sobre la materia y los propios datos de nuestra encuesta así parecen confirmarlo. Entre los españoles encuestados que emigraron entre 1976 y 1990, este tipo de motivos es aducido por cerca de 65 por ciento (casi dos de cada tres) como principal causa de salida de España. Entre los que lo hicieron en la última década del siglo pasado y el primer lustro

\footnotetext{
${ }^{7}$ Así lo pone de manifiesto, por ejemplo, Vidal Rodríguez (2005: 14) en su tesis sobre la emigración gallega a Cuba entre 1898 y 1968: "Los ancianos emigrantes entrevistados en la isla en la última década del siglo XX suelen aducir como causas principales de su decisión, además de las mayoritarias motivaciones económicas, las de índole sicosocial: la huída del servicio militar, la inducción, la emulación del indiano triunfador o el espíritu aventurero de la juventud, y no pocos afirman haber emigrado por circunstancias estrictamente personales o familiares, e incluso por amor".
} 
del siglo actual, este tipo de motivos es esgrimido por algo más de 55 por ciento. Esta proporción se reduce a 45 por ciento entre quienes emigran en 2008-2010, a 40 por ciento en 2011, y a poco más de 30 por ciento en 2012.

Como en el caso de los motivos laborales y económicos, el análisis de los datos de manera más desagregada permite apreciar diferencias significativas en el papel ejercido en el flujo emigratorio por los diversos motivos que integran este amplio subconjunto (Figura 4).

Figura 4: Principal motivo para emigrar de España (formativos, familiares y otros) 1976-2012, según año (periodo) de salida

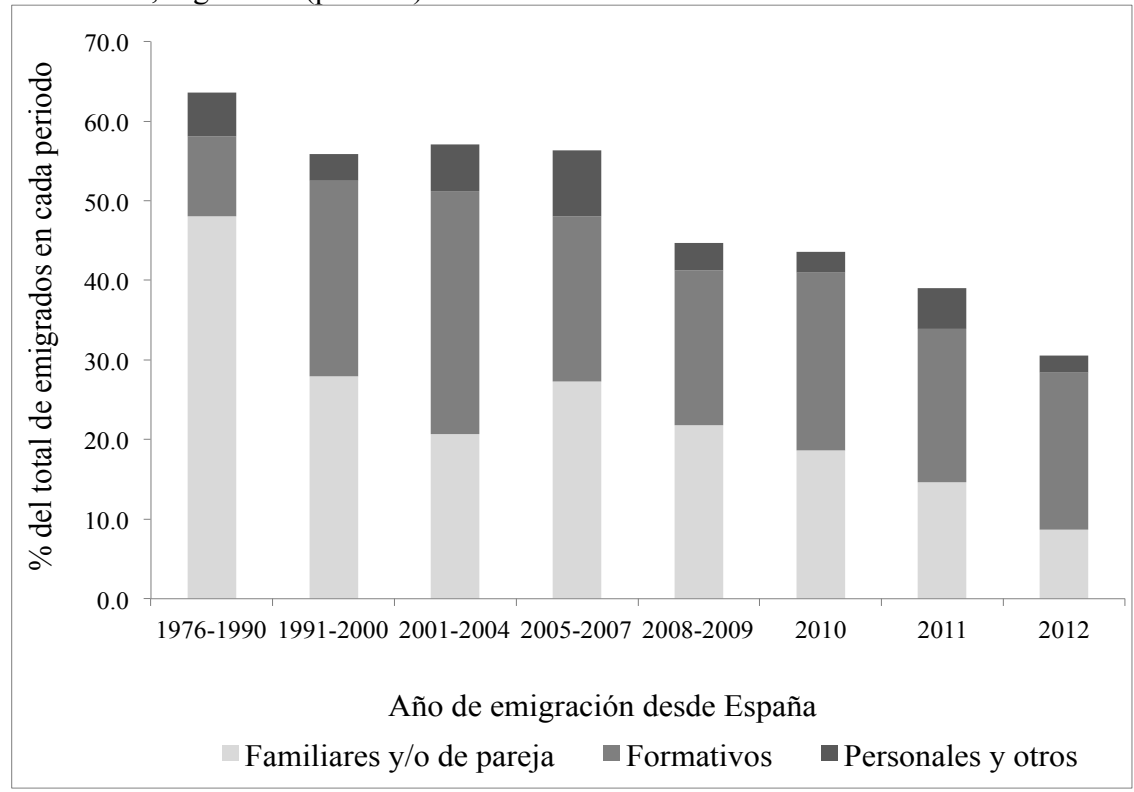

Fuente: elaboración propia con base en la Encuesta sobre la situación de los españoles en el extranjero 2012.

\section{Formativos (estudios y/o aprendizaje de idiomas)}

El deseo de ampliar y/o mejorar la formación de cara a tener más y mejores oportunidades, en la vida en general y el mercado laboral en particular, es desde hace algunas décadas uno de los principales motivos por los que muchas personas salen de su país para residir, de forma más o menos temporal, en el extranjero. Este tema ha sido objeto de análisis específico en los últimos años en diversos trabajos (Senent, 2007; Comisión, 2009; Pawlowska, 2011; García Palma, 2013). La propia OIM en varios de sus informes ha destacado la importancia de esta forma de movilidad (OIM, 
2008 y 2013, especialmente) a la que incluso apoya y facilita en muchos países.

Este tipo de motivos ha venido siendo desde las décadas finales del siglo XX hasta el primer lustro del siglo actual una de las principales causas de salida de España y emigración al extranjero. La entrada de España en la Comunidad Europea en 1986, así como el incremento de las posibilidades para desplazarse y estudiar en el extranjero, han servido de catalizadores para ello. Sirva como dato que ha pasado de representar diez por ciento entre los emigrados en 1976-1990, a 25 por ciento entre los que lo hacen en la década de los 90 del siglo XX, y 25 por ciento entre quienes lo hacen en el primer lustro del siglo actual. Entre los que emigran en 2001-2002 es el tipo de motivos con mayor prevalencia (en torno al 40 por ciento) como principal causa de emigración. Entre los emigrados a partir de 2006 su peso relativo se reduce un poco para situarse en algo menos de 20 por ciento (casi uno de cada cinco).

Cabe reseñar, no obstante, una evolución algo diferenciada como principal causa de emigración entre los motivos que integran este subconjunto de modalidades migratorias. Los estudios y la formación han reducido progresivamente su peso relativo en la última década, pasando de representar 20 por ciento entre los emigrados en el primer lustro del siglo actual, a algo menos de 10 por ciento entre los que lo han hecho posteriormente, alcanzando sus niveles más bajos (en torno a siete por ciento) entre quienes salieron de España en 2011-2012. La ampliación y mejora de la oferta formativa en España, así como el elevado costo de la educación superior en el extranjero, han podido, sobre todo en un contexto de crisis, contribuir a reducir el peso relativo, que no absoluto, de esta forma de migración.

Por el contrario, el aprendizaje o perfeccionamiento de idiomas ha mantenido de forma más o menos constante su peso relativo entre los emigrados en la última década, experimentando un ligero, pero sensible, crecimiento en los últimos años. Ha pasado de ser esgrimido como la principal causa de salida de España por ocho por ciento de los emigrados en 2001-2007, a diez por ciento y 12 por ciento entre los que lo hacen en 2008-2010 y 20112012 respectivamente. Su peso, ya importante entre los que se desplazan fuera de España para la realización de estudios universitarios (Belvis Pons et al., 2007), se acrecienta en estos momentos de crisis económica con la adición de otros colectivos que valoran el conocimiento de idiomas como competencia básica para la inserción y mejora laboral. 
Mejora ingles y búsqueda de trabajo (solemos buscar trabajo para pagarnos la estancia aquí). ¿Por qué elegiste ese país como destino? estudio del inglés británico (Hombre, emigra en 2011 al Reino Unido con 25 años).

Estudiar posgrado en una universidad federal brasileña. ¿Por qué elegiste ese país como destino? Porque siempre me ha fascinado la música brasileña, estudié portugués en la carrera y adoro Brasil! Y porque hay becas para estudiar posgrados (Hombre, emigra en 2010 a Brasil con 25 años).

\section{Familiares y/o de pareja}

Los motivos familiares y/o de pareja (la emigración "por amor" en no pocos casos, tal como la califican sus propios protagonistas) tienen un importante protagonismo como causa principal de salida de España para residir en el extranjero. Varios trabajos recientes se han hecho eco de la importancia y singularidad de este tipo de migración en las últimas décadas (Bodoque y Soronellas, 2009, Roca et al., 2012).$^{8}$ Este motivo también ha merecido, a nivel internacional, una atención específica por parte de la OIM (2008 y 2011).

Según los datos de la encuesta, casi la mitad de los emigrados entre 1976 y 1990 aduce este tipo de motivos como principal causa de salida de España. Entre los emigrados durante la última década del siglo XX y la primera del actual, su nivel de prevalencia se reduce significativamente, situándose en el entorno de 25 por ciento, pero sigue siendo hasta prácticamente 2008 (inicio de la crisis) el principal motivo aducido para salir de España. Entre los emigrados a partir de dicho año su peso relativo se reduce paulatinamente: se sitúa algo por debajo de 20 por ciento entre quienes salen en 2009-2010, de 15 por ciento en 2011 y de 10 por ciento en 2012.

Por mi mujer, es mexicana (Hombre, emigra en 2010 a México con 34 años).

\section{Personales y otros}

La emigración o salida de un país para residir en el extranjero puede estar motivada, obviamente, por otros tipos de motivos diferentes a los anteriores. Si en el pasado tuvieron en España mucho peso las migraciones forzadas por motivos religiosos (expulsión de los judíos y moriscos, de los

\footnotetext{
${ }^{8}$ Son, no obstante, cada vez más los trabajos sobre la emigración española en periodos precedentes que ponen el énfasis en los motivos familiares y de pareja como principal causa de salida de España, especialmente de las mujeres. En el trabajo de Pérez-Fuentes et al. (2009), por ejemplo, sobre la emigración española a América se recogen testimonios de varias personas (mujeres en todos los casos) que "confiesan haber emigrado por amor". En el trabajo de Fernández Asperilla (2000) se destaca el importante peso que pasó a jugar la reagrupación familiar en la emigración española a Europa cuando a mediados de la década de los setenta los países receptores detuvieron el flujo migratorio hacia los mismos.
} 
jesuitas, etc.) y políticos (el provocado por la Guerra Civil de 1936-1939 quizás sea el más emblemático), en las últimas décadas, sobre todo tras el advenimiento de la democracia, estos últimos han reducido al mínimo su importancia. A partir de entonces, entre los emigrantes españoles han ido ganando peso como razón principal para salir de España otros motivos de carácter personal y psicosocial (el deseo de exploración y aventura, cambiar de aires, la mejora de la calidad de vida y el bienestar individual, entre otros), propios de una sociedad del bienestar, equiparándonos con ello a lo que viene ocurriendo desde hace más tiempo en otros países desarrollados.

Según los datos de la encuesta, estos motivos tienen una prevalencia baja entre los emigrados en las últimas décadas. Constituyen la principal causa de salida de España de solo cinco por ciento, aproximadamente, de los emigrados desde $1976^{9}$ hasta 2012. Dicha proporción solo es algo superior, en torno a ocho por ciento, entre los emigrados en 2003-2007, período que coincide con el momento de mayor bonanza económica en nuestro país. Entre los emigrados a partir de 2008 su peso relativo se ha reducido significativamente a favor de los anteriores, situándose por debajo de cinco por ciento. ${ }^{10}$

Ampliar la visión del mundo, inquietudes personales, así como un ampliar el desarrollo profesional (Mujer, emigra en 2006 a México con 27 años).

\section{Conclusiones}

Los españoles han emigrado a lo largo de la historia siguiendo motivaciones diversas. Los motivos políticos, pero sobre todo los de carácter laboral y económico, han sido los principales catalizadores de las oleadas emigratorias que se han producido en los siglos XIX y XX. Informaciones directas recogidas a través de testimonios directos de sus propios protagonistas u observadores privilegiados, así como, en algunos casos, obtenidas mediante encuestas, atestiguan el predominio absolutamente mayoritario de los motivos laborales y económicos en las grandes oleadas emigratorias de 1880-1930, que tuvo América como destino fundamental, y la del tercer

\footnotetext{
${ }^{9}$ Entre los encuestados que había emigrado entre 1951 y $1975(\mathrm{~N}=87)$, casi 40 por ciento indicaron otros motivos como principal razón de salida de España. Es muy probable, como hemos podido constatar en las entrevistas realizadas, que muchos de estos casos correspondan a motivos de carácter político.

${ }^{10}$ En un trabajo reciente sobre la nueva emigración española a Alemania se llevó a cabo una encuesta on-line a 300 jóvenes españoles llegados a la ciudad de Berlín en los últimos años. Los resultados de la misma ponen de manifiesto que los motivos personales han sido los de mayor prevalencia para emigrar a esta ciudad (Faraco et al., 2013: 176). Los autores del trabajo indican, no obstante, la especificidad del caso berlinés respecto al resto de ciudades y el conjunto de Alemania.
} 
cuarto del siglo XX, que desde principios de la década de los sesenta tuvo como principales receptores a los países de Europa occidental.

Las sustanciales transformaciones que se han producido en las últimas décadas en la sociedad y economía española (restauración de la democracia, incorporación a la Unión Europea, crecimiento económico, desarrollo del Estado del Bienestar, mejora notable de la educación en todos sus niveles, etc.) han tenido importantes efectos en la naturaleza y peso específico de los motivos que inducen a los españoles a emigrar. Durante el último cuarto del siglo XX hasta mediados de la primera década del siglo actual la emigración española no solo ha reducido sensiblemente su volumen, en un contexto marcado por el predominio absoluto de la inmigración, sino que además se ha transformado profundamente en sus formas adaptándose a la globalización, la libre circulación en el espacio europeo, y los intensos procesos de internacionalización social y económica que se verifican en nuestro país.

Aunque no se ha estudiado suficientemente aún la emigración que se ha desarrollado en las últimas décadas del siglo XX y la primera del actual hasta el inicio de la crisis, las informaciones disponibles, así como los propios datos de nuestra encuesta y los análisis llevados cabo en este trabajo, apuntan a que se han producido cambios relevantes respecto al período anterior. Por un lado, se ha producido una mayor diversificación de los motivos para emigrar, así como de su propia naturaleza, homologándonos progresivamente en este sentido a los estándares presentes en los países más desarrollados. Por otra, todo parece indicar que han ganado peso relativo los motivos familiares y de pareja, los relacionados con la mejora formativa y los de índole personal.

Los motivos familiares y de pareja han ganado peso, convirtiéndose en los de mayor prevalencia para los españoles emigrados en el último cuarto del siglo XX y el primer lustro del siglo actual. Los motivos relacionados con la formación y adquisición de destrezas y competencias (realización de estudios, aprendizaje y perfeccionamiento de idiomas, etc.), han irrumpido con notable fuerza, perdiendo el carácter relativamente minoritario e incluso elitista que tuvieron en tiempos pretéritos. Otros tipos de motivos, como los relacionados con el desarrollo y realización personal, en sus múltiples formas, también han pasado a ocupar un lugar importante en la decisión de emigrar. Los motivos de orden político, por su parte, han reducido su peso al mínimo, siendo solo relevantes por una exigua minoría.

Durante este periodo, los motivos laborales y económicos, aún reduciendo su protagonismo a favor de los anteriores, han seguido siendo im- 
portantes en la decisión de emigrar para una gran parte de los españoles que han salido del país durante estos años. Quizás lo más novedoso, en este sentido, ha sido, por una parte, la diversificación interna de los mismos, experimentando un notable crecimiento algunos relativamente minoritarios anteriormente como los relacionados con el desplazamiento y la expatriación (destino laboral, cooperación, etc.), y por otra, que se han planteado más frecuentemente en términos de oportunidad (desarrollo profesional) que de necesidad como ocurría de forma mayoritaria entre quienes emigraron en períodos precedentes.

Los propios instrumentos normativos para la gobernanza de la emigración que cristalizan en España durante estos años (Estatuto de la Ciudadanía Española en el Exterior, etc.) reflejan claramente la nueva situación. Muy distinta de la que inspiró las leyes y reglamentos de emigración promulgadas a lo largo de la pasada centuria.

En la actualidad los movimientos migratorios, teniendo en cuenta, por un lado, el ejercicio del derecho a la libre circulación en el contexto de la Unión Europea, y por otra la globalización de la economía, han alcanzado una dimensión y una significación distinta. En los países desarrollados, en los que el Estado satisface las necesidades básicas de su ciudadanía, el desplazamiento a otro país responde a motivaciones de distinta índole que persiguen ampliar las expectativas personales y profesionales o mejorar la calidad de vida, como es el caso de los funcionarios públicos y trabajadores al servicio de la Administración española en el exterior, los cooperantes y los trabajadores y profesionales de las empresas españolas destinados temporalmente en el exterior" (Ley 40/2006 del Estatuto de la Ciudadanía Española en el Exterior, Exposición de Motivos, II.7).

Los análisis llevados a cabo en este trabajo ponen de relieve un crecimiento desde mediados de la primera década del siglo actual del peso de los motivos laborales, de forma simultánea al que se produce en el flujo emigratorio. Durante el segundo lustro de dicha década son los motivos relacionados con el desarrollo profesional y la expatriación los principales protagonistas de este crecimiento. El estallido de la crisis económica en 2008 y la agudización de sus efectos en los años subsiguientes no solo ha espoleado de nuevo la emigración, llevándola a cotas no registradas desde mediados de la década de los 70 del pasado siglo, sino que, además, ha operado de manera muy importante en los motivos de los españoles para tomar dicha decisión.

Desde fines de dicha década, pero sobre todo, principios de la presente, son los motivos relacionados con la falta de empleo y de oportunidades 
laborales quienes se convierten en los principales impulsores del flujo emigratorio. Es decir, de una emigración laboral planteada mayoritariamente en términos de oportunidad o mejoría, se ha pasado en la presente década a otra en términos de necesidad. Necesidad, no asociada a la miseria o la extrema pobreza como pudo ser frecuente en períodos precedentes de nuestra historia, pero si a la práctica incapacidad de desarrollar en España un proyecto vital y profesional.

Los resultados expuestos en este trabajo relativos a las motivaciones de la emigración en los últimos años coinciden en buena medida con los ofrecidos por otros autores (INJUVE, 2013; González y Romera, 2014; OIM, 2014). No obstante, ponen mayor énfasis en el papel ejercido por los motivos relacionados con el desempleo y la falta de oportunidades en el incremento del flujo emigratorio, especialmente desde 2011. En este sentido, coincide bastante con los trabajos llevados a cabo por la Universidad de Cork para el caso irlandés (Glynn et al., 2013).

Aunque los análisis llevados a cabo en este artículo tienen el año 2012 como referencia temporal final, diversas razones nos inducen a pensar que este tipo de motivos ha podido seguir marcando el ritmo del flujo migratorio en los últimos años. Por una parte, el notable crecimiento del flujo emigratorio durante los años subsiguientes hasta la actualidad, en un contexto marcado por la agudización (2013) e inercia de los efectos de la crisis económica, que opacan la tímida recuperación experimentada a partir de 2014. Por otra, los propios datos e informaciones sobre el fenómeno recogidas mediante entrevistas en los trabajos que venimos realizando para el caso de la nueva emigración española a los países iberoamericanos (Rodríguez Fariñas et al., 2015a, 2015b, 2016a, 2016b, 2017), así como en algunas encuestas realizadas sobre la intención y motivaciones para emigrar de los jóvenes españoles (Zurich, 2013; Vodafone Institute, 2014).

\section{Agradecimientos}

Este artículo es resultado de los trabajos de investigación que se llevan a cabo en el marco de los proyectos "Migraciones en y entre España y República Dominicana" (FUASDSEN, AACID) y "La emigración española actual: continuidades, cambios y tendencias" (Proyectos Puente - EPC, Universidad de Huelva). Deseo expresar mi agradecimiento al Dr. Antonio Luis Hidalgo Capitán (Universidad de Huelva) por su colaboración y apoyo en estas investigaciones. 


\section{REFERENCIAS BIBLIOGRAFICAS}

Aceituno, Pedro, 2008, “Tercer informe INNOVACEF: la respuesta de los científicos españoles en el extranjero y aportaciones desde la Federación de Jóvenes Investigadores", en Revista de Trabajo y Seguridad Social del Centro de Estudios Financieros, pp. 305-306.

ADM, 2000, Guideline for Online Surveys, Arbeitskreis Deutscher Markt- und Sozialforschungsinstitute, Frankfurt am Main.

ADM, 2001, Standards for Quality Assurance for Online Surveys, Arbeitskreis Deutscher Markt- und Sozialforschungsinstitute, Frankfurt am Mainm.

AEC, 2014, Guía para la realización de estudios de análisis de la demanda y de evaluación de la satisfacción de los usuarios, Ministerio de Hacienda y Administraciones Públicas - Agencia Estatal de Evaluación de las Políticas Públicas y la Calidad de los Servicios, Madrid.

Bastida Domínguez, María, 2007, "El capital humano internacional como fuente de ventaja competitiva”, en Boletín económico del ICE, núm. 2917, pp. 59-73.

Belvis Pons, Esther; Pineda Herrero, Pilar; Moreno Andrés, María Victoria, 2007, "La participación de los estudiantes universitarios en programas de movilidad: factores y motivos que la determinan", en Revista Iberoamericana de Educación, vol. 45, núm. 5, pp. 1-14.

Biacabe, Jean-Luc et Robert, Simon, 2014, Les Français de l'étranger. La expatriation des Français, quelle réalité ?, Chambre de commerce et díndustrie de región Paris - Île de France, Paris.

Bodoque Puerta, Yolanda y Soronellas Masdéu, Montserrat, 2009, "Parejas en el espacio transnacional: los proyectos de mujeres que emigran por motivos conyugales", en Migraciones internacionales, vol. 5, núm. 3, pp. 143-174.

Cabezón Fernández, María Jesús y Sempere Souvannavong, Juan David, 2017, "El paro o Argelia: la expatriación de los españoles en Argelia como salida laboral", en Migraciones, 43 (2017), pp. 15-38.

Cantor, Guillermo, 2002, "La Triangulación Metodológica en Ciencias Sociales", en Cinta de Moebio. Revista Electrónica de Epistemología de Ciencias Sociales, 13, pp. 58-69.

Cañibano, Carolina; Otamendi, Javier y Solís, Francisco, 2010, “Investigación y movilidad internacional: análisis de las estancias en centros extranjeros de los investigadores andaluces", en Revista española de documentación científica, vol. 33 (3), pp. 428-457.

Castillo Castillo, José, 1981, La emigración española en la encrucijada. Estudio empírico de la emigración de retorno, Centro de Investigaciones Sociológicas, Madrid.

Cea d'Ancona, Ma Ángeles, 2004, Métodos de encuesta. Teoría y práctica, errores y mejora, Editorial Síntesis, Madrid. 
COMISIÓN DE LAS COMUNIDADES EUROPEAS, 2009, Libro verde. Fomentar la movilidad en la formación de los jóvenes, Comisión de las Comunidades Europeas, Bruselas.

CONSEJO SUPERIOR DE MISIONES, 1962, España misionera: Catálogo de los misioneros y de los religiosos españoles en el extranjero, Ediciones España Misionera, Madrid.

Contreras Soto, Ricardo, 2008, Migración, percepción cultural del trabajador periférico en el centro (constitución simbólica en contextos estructurados), Tesis de Maestría en Antropología, Universidad Autónoma de Querétaro. Santiago de Querétaro, México.

COORDINADORA DE ONG PARA EL DESARROLLO, 1990, Voluntariado y cooperación al desarrollo, La Acción Voluntaria. Cuadernos de la Plataforma, núm. 11, Plataforma para la Promoción del Voluntariado, Madrid.

De Jong, Gordon F. and Gardner, Robert W. (eds.), 1981, Migration Decisión Making: Multidisciplinary Approaches to Microlevel Estudies in Developep in Developing Countries, Pergamon Policie Studies, New York.

Díaz de Rada, Vidal, 2004, "Encuestas en Internet. Algo más que una simple versión mejorada de la tradicional encuesta autoadministrada", en Investigación y Marketing, 82, pp. 45-56.

Díaz de Rada, Vidal, 2010, "Eficacia de las encuestas por internet: un estudio preliminar", en Revista Española de Sociología, 13, pp. 49-79.

Díaz de Rada, Vidal, 2011, "Encuestas con encuestador y administradas por Internet. ¿Proporcionan resultados comparables?”, en Revista Española de Investigaciones Sociológicas, 136, pp. 49-90.

Díaz de Rada, Vidal, 2012, "Ventajas e inconvenientes de la encuesta por Internet", en Papers. Revista de Sociología, 97(1), pp. 193-223.

Ebanks, Edward G., 1993, Determinantes socioeconómicos de la migración interna, con especial referencia a la región de América Latina y el Caribe, Serie E, núm. 38, Centro Latinoamericano de Demografía (CELADE), Santiago de Chile.

Faraco Blanco, Cristina; Castillo Castilla, Esther; Krausslach, Marianne; Montero Lange, Miguel, 2013, Proyecto nueva emigración. Informe Final, Coordinadora Federal del Movimiento Asociativo en la RFA.

Fawcett, James T. and De Jong, Gordon F., 1982, "Reasons for moving and migration behavior", en Naciones Unidas, National Migration Surveys: Guidelines for Analyses, pp. 109-131, New York.

Fernández Asperilla, Ana, 2000, "Estrategias migratorias. Notas a partir del proceso de la emigración española en Europa (1959-2000) ", en Migraciones y Exilios, Cuadernos de la Asociación para el estudio de los exilios y migraciones ibéricos contemporáneos, núm. 1, pp. 67-94.

Fernández De Pinedo, Emiliano, 1988, "Los movimientos migratorios vascos, en especial hacia América", en Nicolás Sánchez Albornoz (comp.), Españoles ha- 
cia América. La emigración en masa, 1880-1930, pp. 105-122, Alianza Editorial, Madrid.

García Palma, Jonathan Jesús, 2013, "Movilidad estudiantil internacional y cooperación educativa en el nivel superior de educación”, en Revista Iberoamericana de Educación, núm. 61, pp. 59-76.

Glynn, Irial; Kelly, Tomas y Macéinrí, Piaras, 2013, Irish Emigration in an Age of Austerity, University College Cork.

Gómez Frías, Raquel; Molina-Palomero, Olaya; Badenes-Ribera, Laura; FríasNavarro, Dolores, 2015, "Razones para emigrar de los estudiantes universitarios: ¿continuar con la formación académica?”, en Tortosa Ibáñez, María Teresa, Álvarez Teruel, José Daniel y Pellín Buades, Neus, Coordinadores XIII Jornadas de Redes de Investigación en Docencia Universitaria. Nuevas estrategias organizativas y metodológicas en la formación universitaria para responder a la necesidad de adaptación y cambio, pp. 3111-3123. Universidad de Alicante - Vicerrectorado de Estudios, Formación y Calidad - Instituto de Ciencias de la Educación (ICE).

González Becerril, Juan Gabino; Montoya Arce, Bernardino Jaciel; López Vega, Rafael, 2012, Encuesta sobre Migración de Mexiquenses a Estados Unidos (EMMEU 2009), Universidad Autónoma del Estado de México, Toluca.

González Enríquez, Carmen y Martínez Romera, José Pablo, 2014, Country Focus: Migration of Spanish nationals during the crisis. Real Instituto Elcano, Madrid.

González Enríquez, Carmen, 2013, ¿Emigran los españoles?, Real Instituto Elcano.

González Ferrer, Amparo, 2013, La nueva emigración española. Lo que sabemos y lo que no, Laboratorio de Alternativas. Colección: Zoom Político, núm. 2013/18.

Gozálvez Pérez, Vicente, 1994, “Descolonización y migraciones desde el África española (1956-1975) ”, en Investigaciones geográficas, núm. 12, pp. 45-84.

Hampe Martínez, Teodoro, 1992, "Los funcionarios de la monarquía española en América. Notas para una caracterización política, económica y social", en Revista Interamericana de Bibliografía, vol. 42, núm. 3, pp. 431-452.

Iglesias Fernández, Carlos; Llorente Heras, Raquel y Dueñas Fernández, Diego, 2011, "La movilidad internacional de los doctores españoles: ¿cuáles son sus determinantes?", en Investigaciones de Economía de la Educación, vol. 6, pp. 593-611.

ILO, 2015, ILO global estimates on migrant workers. Results and methodology. Special focus on migrant domestic workers, International Labour Organization, Geneva.

INJUVE, 2013, La emigración de los jóvenes españoles en el contexto de la crisis. Análisis y datos de un fenómeno difícil de cuantificar. Observatorio de la Juventud en España, Madrid. 
Jannuzzi, Paulo de Martino, 2000, “Tasas específicas por motivos y acompañantes de la migración: una contribución a la interpretación y al uso de modelos de patrones etarios de migración", en Notas de población, pp. 17-53.

Laparra, Miguel y Anaut, Sagrario (coords.), 2009, Estudio sobre la evolución y situación actual en el mundo de la población emigrante de Navarra, Universidad Pública de Navarra, Pamplona.

MTySS, 1986, Panorama de la emigración española a Europa, Ministerio de Trabajo y Seguridad Social, Madrid.

Murray, Rosemary; Hardong, David; Gillespie, Rebecca and Arora, Harsimran, 2012, Emigration from the UK. Research Report 68, November 2012, Home Office, London.

OIM, 2008, Informe sobre las migraciones en el mundo 2008. La gestión de la movilidad laboral en una economía mundial en plena evolución, Organización Internacional de las Migraciones, Ginebra.

OIM, 2012, La Emigración de profesionales cualificados: una reflexión sobre las oportunidades para el desarrollo, Organización Internacional para las Migraciones (Representación en España), Madrid.

OIM, 2013, Informe sobre las migraciones en el mundo 2013. El bienestar de los migrantes y el desarrollo, Organización Internacional de las Migraciones, Ginebra.

OIM, 2014, Aproximación a la Situación de los Españoles Emigrados: Realidad, Proyecto, Dificultades y Retos. Organización Internacional para las Migraciones (Representación en España), Madrid.

Palazón Ferrando, Salvador, 1995, Capital humano español y desarrollo latinoamericano. Evolución, causas y características del fujo migratorio (1882-1990), Instituto de Cultura Juan Gil-Albert, Alicante.

Parlamento Europeo, 2007, "Reglamento (CE) B 8 862/2007 del Parlamento Europeo y del Consejo de 11 de julio de 2007 sobre las estadísticas comunitarias en el ámbito de la migración y la protección internacional", en Diario Oficial de la Unión Europea, 31 de julio de 2007, L 199.

Pascual Faura, Marcelo y Escalera Izquierdo, Gregorio, 2009, "Consideraciones previas al proceso de expatriación", en Boletín económico del ICE, núm. 2956, 25-33.

Pawlowska, Ewa, 2011, El turismo académico. Un análisis económico para el caso de Galicia. Tesis Doctoral. Universidad de Santiago de Compostela.

Pérez-Fuentes Hernández, Pilar; Pérez Pérez, José Antonio; Sallé Alonso, M ${ }^{\mathrm{a}}$ Ángeles, 2009, Memorias de la emigración española a América, Fundación Directa - Ministerio de Trabajo e Inmigración, Madrid.

Pérez, Ángela, 2013, "El Estatuto del Cooperante: virtudes, carencias y retos", en Fernández Franco, Lorenzo y Román Marugán, Paloma (coords.), Manual de Cooperación al Desarrollo, pp. 53-76. Madrid, Editorial Síntesis. 
Reino de España, 2006, “Ley 40/2006 del Estatuto de la Ciudadanía Española en el Exterior", en $B O E$, núm. 299, de 15 de diciembre de 2006, páginas 44156 a 44166.

Reques Velasco, Pedro y De Cos Guerra, Olga, 2003, "La emigración olvidada: la diáspora española en la actualidad”, en Papeles de Geografía, núm. 37, pp. 199-216.

Roca, Jordi; Soronellas, Montserrat; Bodoque, Yolanda, 2012, "Migraciones por amor: diversidad y complejidad de las migraciones de mujeres", en Papers, 97/3, pp. 685-707.

Rodríguez Fariñas, María Jara; Romero-Valiente, Juan Manuel; Hidalgo-Capitán, Antonio Luis, 2015a, "Los exiliados económicos. La tercera oleada de emigración española a Chile”, en Revista de Geografía Norte Grande, 61, pp. 107-133.

Rodríguez Fariñas, María Jara; Romero-Valiente, Juan Manuel; Hidalgo-Capitán, Antonio Luis, 2015b, "Los exiliados económicos. La nueva emigración española a Ecuador”, en OBETS. Revista de Ciencias Sociales, 10 (2), pp. 397-435.

Rodríguez-Fariñas, Jara., Romero-Valiente, Juan Manuel e Hidalgo-Capitán, Antonio Luis, 2017, "Los exiliados económicos. La nueva emigración española a Argentina (2008-2015)", en Iberoamerican Journal of Development Studies, 6 (2), pp. 72-96.

Rodríguez-Fariñas, María Jara., Romero-Valiente, Juan Manuel e Hidalgo-Capitán, Antonio Luis, 2016a, "Los exiliados económicos. La nueva emigración española a México", en Scripta Nova. Revista electrónica de Geografía y Ciencias Sociales, vol. 20, núm. 531, 1 de marzo de 2016. Universidad de Barcelona. Disponible en http://www.ub.edu/geocrit/sn/sn-531.pdf

Rodríguez-Fariñas, María Jara., Romero-Valiente, Juan Manuel e Hidalgo-Capitán, Antonio Luis, 2016b, "Los exiliados económicos. La nueva emigración española a Brasil (2008-2015)", en Navegar. Revista de Estudos de E/Imigraçao, 2(3), pp. 137-162.

Romero-Valiente, Juan Manuel, 1998, Las migraciones exteriores de República Dominicana. Intercambios migratorios con España, Servicio de Publicaciones de la Universidad de Huelva.

Romero-Valiente, Juan Manuel, 1999, “Españoles en República Dominicana: proceso migratorio y perfil sociodemográfico", en Estudios Sociales, núm. 118, pp. $85-94$.

Romero-Valiente, Juan Manuel, 2003, “Migraciones”, en Arroyo Pérez, Andrés (director), Tendencias demográficas durante el siglo XX en España, pp. 209-253, Instituto Nacional de Estadística, Madrid.

Romero-Valiente, Juan Manuel, 2012, La movilidad exterior de los españoles y las españolas en la actualidad. Informe Final, Fundación Universidad de Huelva - Dirección General de Migraciones (Ministerio de Empleo y Seguridad Social). 
Romero-Valiente, Juan Manuel, 2016, "Los flujos migratorios en las estadísticas de origen y destino: la emigración de españoles a Europa", en Cuadernos Geográficos, 55(2), pp. 151-172.

Romero-Valiente, Juan Manuel, 2017, "Patrones y diferencias socio-demográficas en el registro estadístico de la emigración española actual", en Estudios Demográficos y Urbanos, vol. 32, núm. 1, pp. 163-197.

Romero-Valiente, Juan Manuel, 2018, 'La emigración de españoles al extranjero (2002-2011): dimensiones y características geodemográficas", en Iberoamerican Journal of Development Studies, forthcoming.

Rubio, Javier, 1973, "Encuesta sobre las coordenadas motivacionales, socioprofesionales y culturales de la emigración española en el Languedoc", en Revista Internacional de Sociología, 31 (5).

Sánchez Alonso, Blanca, 1995, Las causas de la emigración española, 1880-1930, Alianza Editorial, Madrid.

Sánchez Carrión, Juan Javier; Segovia Guisado, José Manuel; Sánchez Meseguer, Paula, 2012, "Las encuestas en Internet", en Arroyo Menéndez, Milán y Sádaba Rodríguez, Igor (coords.), Metodología de la investigación social. Técnicas innovadoras y sus aplicaciones, pp. 79-108, Editorial Síntesis, Madrid.

Sánchez Ron, José Manuel, 1988, "La Junta para Ampliación de Estudios e Investigaciones Científicas ochenta años después", en Sánchez Ron, José Manuel (coord.), 1907-1987: la Junta para Ampliación de Estudios e Investigaciones Cientificas ochenta años después, pp. 1-61. Consejo Superior de Investigaciones Científicas, Madrid.

Senent Sánchez, Joan María, 2007, "La evolución de la movilidad académica en Europa, en la perspectiva de la creación del Espacio Europeo de Educación Superior", en Revista Española de Educación Comparada, 13, pp. 361-399.

Sepúlveda Muñoz, Isidro, 1992, "Diplomáticos y cónsules españoles en América, 1892-1936", en Espacio Tiempo y Forma. Serie V, Historia Contemporánea, núm. 5, pp. 397-412.

Serrano Carvajal, José, 1966, La emigración española y su régimen jurídico. Instituto de Estudios Políticos, Madrid.

Triandafyllidou, Anna and Gropas, Ruby, 2014, "Voting with their feet": highly skilled emigrants from Southern Europe", in American Behavioral Scientist, november, vol. 58 (12), pp. 1614-1633.

UNITED NATIONS, 1982, National migration surveys: $x$ guidelines for analyses, United Nations, New York.

UNITED NATIONS, 1998, Recommendations on statistics of international migration. Revision 1, Statistical Papers Series M, No. 58, Rev. 1, United Nations - Department of Economic and Social Affairs - Statistics Division, New York. 
Vázquez, Alejandro y Estrada, Baldomero, 1992, "Causas de la emigración y tipología de emigrantes", en Historia general de la emigración española a Iberoamérica. Volumen 1, Historia 16, Madrid.

Vidal Rodríguez, José Antonio, 2005, La emigración gallega a Cuba: trayectos migratorios, inserción y movilidad laboral, 1898-1968, Consejo Superior de Investigaciones Científicas, Madrid.

VODAFONE INSTITUTE SURVEY, 2014, Talking about a Revolution: Europe's Young Generation on Their Opportunities in a Digitised World - A Study Across Eight European Countries, Vodafone Institute for Society and Communications.

Ybarra, María Concepción, 2000, "La otra presencia de España en el exterior: la cooperación internacional", en Espacio, Tiempo y Forma, Serie V, $\mathrm{H}^{\mathrm{a}}$ Contemporánea, t. 13, pp. 253-270.

Zafra-Cotrina, Julio, Edgar, 2006, "La cooperación misionera en la Iglesia y sus estructuras organizativas", en Cuadernos Doctorales, vol. 21, pp. 367-428.

Zurich, 2013, Global Zurich Survey. Emigration, Zurich Insurance Group.

\section{RESUMEN CURRICULAR DEL AUTOR}

\section{Juan Manuel Romero Valiente}

Doctor en Geografía por la Universidad de Sevilla, en 1996. Actualmente es Profesor Titular del Departamento de Historia II y Geografía en la Universidad de Huelva e Investigador del Centro de Investigación en Migraciones (CIM) de la misma. Miembro Titular de FLACSO-España desde 2014. Desarrolla una línea de investigación sobre migraciones internacionales con especial atención a las que se desarrollan en (y entre) España y Latinoamérica. Ha dirigido y redactado el "Estudio sobre la movilidad exterior de los españoles y las españolas en la actualidad" (MEySS, 2012), y escrito varios artículos sobre esta temática en revistas de impacto: Revista de Geografia Norte Grande, Scripta Nova, Obets.

Dirección electrónica: valiente@uhu.es

Artículo recibido el 26 de febrero de 2016 y aprobado el 3 de julio de 2017. 